\title{
Correlation analysis of bulb yield with growth and yield components of garlic (Allium sativum L.)
}

\author{
*S. M. Zakari, H. Haruna and A. A. Aliko \\ Department of Plant Biology, Bayero University Kano, Nigeria. \\ [Corresponding Authir: E-mail: smzakari.bot@buk.edu.ng]
}

\begin{abstract}
Two experiments were conducted under irrigation at the Institute for Agricultural Research (I.A.R) Kadawa in the Sudan Savanna zone of Nigeria during 2007/2008 and 2008/2009 (Nov- Mar) dry seasons to study the relationship among growth, yield components and bulb yield of garlic (ex- Kofa var). Growth parameters studied included plant height, number of leaves, total dry matter, crop growth rate (CGR), relative growth rate (RGR) while the yield parameters studied included fresh bulb weight, cured bulb weight, bulb diameter, number of cloves/bulb, weight of cloves and cured bulb yield (kg/ha). Results obtained showed a significant and positive correlation between total bulb yield per hectare and growth as well as the other yield characters except RGR in 2007/2008 trial and CGR as well as the number of cloves in 2008/2009 trial. However, for the combined analysis, CGR, RGR and number of cloves were found not have positive correlation with the bulb yield. These characters should therefore, not be aimed at if the aim is to increase/ improve yielding ability of garlic
\end{abstract}

Key Words: Correlation, Kadawa, Sudan Savanna, Garlic, Irrigation, growth and yield components.

\section{INTRODUCTION}

Garlic is the second most widely cultivated species of the genus "Allium after Allium cepa (Huber, 2003). It is believed to have originated from central Asia and spread to all parts of the world and is widely grown in India, Philippines, China, Ethiopia, Kenya and Rome. It is used both as staple food and medicine for several ailments (Bodnar et al., 1997).

In Nigeria, the production of garlic is concentrated in the Northern Guinea and Sudan Savanna ecological zones, where it is mainly grown under irrigation in the dry season. Its diverse distribution can be seen by its diverse common names in different societies. It is called "Tafarnuwa" in Hausa, "Saum" in Arabic, "Aglio" in Italy, "Chesnoc" in Russia, "Lahsan in Hindi, "Ail" in French, "Ayu" in Yoruba, etc. (Aliyu, 2006).

The scope of increasing its production by bringing more areas under cultivation is very limited, because it is grown only in the dry season when other major crops occupy most of the cultivated lands. Rainfall is very scanty during the dry season and frequent irrigation increases its successful production (Islami et al., 2007).

Although, both manure and chemical fertilizers have a potential role in the growth and development of crops, indiscriminate use of fertilizers changes the physical, chemical and biological properties of soil, pollutes the environment and creates health hazards by its toxic residue (Borabash and Kochina, 1987). Manures supply all essential nutrients as well as improve physical, chemical and biological properties of soil and may help boost the production of garlic to peasant farmers. Moreover, despite the ranking of garlic as one of the most important medicinal crops in the world, the present day production level does not meet the demand of the teeming population.

A study conducted by Zakari et al. (2014) reported increase in bulb yield of garlic treated with $10 \mathrm{~kg} / \mathrm{ha}$ of three different types of manure but did not correlate the yield with growth and other yield attributes. Therefore, the objective of 


\section{Nigerian Journal of Basic and Applied Science (June, 2017), 25(1): 58-62}

this study is to determine the simple correlation between all growth, yield components and bulb yield of garlic (Allium sativum L.).

\section{MATERIALS AND METHODS}

Field experiments were conducted during the 2007/2008 and 2008/2009 dry seasons at the Institute for Agricultural Research, Kadawa Station ( $11^{\circ} 3^{\prime} \mathrm{N}, 8^{\circ} 2^{\prime} \mathrm{E}, 500 \mathrm{~m}$ above Sea level) in the Sudan Savanna zone of Nigeria. The correlation between growth parameters, yield components and bulb yield per hectare of a local variety of garlic (ex- Kofa) was evaluated. Mature garlic bulbs were selected and split into cloves, large and medium sized cloves were selected and soaked overnight to remove scale leaves to enhance good sprouting before planting. The field was then prepared and marked out into fifteen basins of $2 \times 1.5 \mathrm{~m}$. Therefore, the gross plot size was $3 \mathrm{~m}$ having 10 rows spaced at $15 \mathrm{~cm}$ apart, an intra-row spacing of $10 \mathrm{~cm}$ and the net plot consists of 6 inner rows of $2 \mathrm{~cm}$ length. Prior to planting, single dose of organic manure at the rate of 10.0 tons/ha (Zakari et al., 2014) was incorporated into the basins by broadcasting method.

Following agronomical practices, measurements on plant heights, numbers of leaves, total dry matter, crop growth rate (CGR) and relative growth rate (RGR) were recorded as growth parameters while fresh bulb weight, cured bulb weight, bulb diameter, number of cloves/bulb and average weight/cloves were taken using five (5) randomly sampled matured air-cured bulbs per plot after harvest as yield parameters. Weights of all bulbs per plot were taken and recorded in grams and subsequently converted to kilograms per hectare. Cured bulb weight per plot(bulb yield/ha) was taken and recorded per plot after harvest and air- curing for 2 weeks, expressed in grams and kilograms per hectare. The correlation analysis was conducted using $\mathrm{R}$ stat.

\section{RESULTS AND DISCUSSION}

The correlation coefficient for the different variables assessed for bulb yield of garlic per hectare showed that garlic bulb yield per hectare was observed to be significantly and positively correlated with all the parameters assessed except RGR in 2007/2008 trial (Table 1) CGR and number of cloves in 2008/2009 trial (Table 2) and CGR, RGR and number of cloves in the combined years analysis (Table 3 ). This may indicate the importance of these parameters as yield contributing factors in garlic. The correlations between most factors in garlic were significant and positive except that between number of leaves and RGR, RGR and cured bulb weight, and bulb yield per hectare in 2007/2008 dry season. The correlations between CGR and most factors were negative and not significant except with bulb yield per hectare where the correlation though positive is not significant (Table 2) in 2008/2009 dry season. No significant correlation was observed between plant height with CGR and RGR, number of leaves and CGR, number of leaves and average weight of cloves, average bulb diameter and average number of cloves, average number of cloves and bulb yield per hectare in 2008/2009 season (Table 2). In the combined analysis plant height and number of leaves were not significantly correlated to CGR and RGR, CGR with all parameters were not significant except with RGR, RGR and only number of cloves correlated, bulb diameter was not significantly correlated with number of cloves, number of cloves was not significantly correlated with weight of cloves and bulb yield per hectare (Table 3).

These observations shows the contributory role of these factors in enhancing bulb yield in garlic, as the coefficient between two variables is the sum of the paths connecting them as reported by Aliuddin, (1980) and Miko et al. (2006).

The positive and significant correlation observed between most of the growth and yield characters studied indicated interdependency amongst the characters and these matrices are of great importance in assisting breeders in establishing and thus selecting those characters 
that influence bulb yield in garlic (Miko et al., 1995) and therefore, help in yield improvements. The increase in plant heights, number of leaves and other positively correlated characters increased the amount of assimilates being produced and translocated to the sink which finally has bearing on the yield. Similar results have been reported by Babaji (1997) and Miko et al., (1995).
The negative and insignificant association between CGR and RGR on bulb yield in both seasons and combined analysis implies that any increase due to selection for CGR or RGR would be accompanied by a corresponding decrease in bulb yield. These characters should therefore not be considered if the aim is to increase yielding ability of garlic; similar results were reported by Bichi (1997) and Babaji (1996).

Table 1: Simple correlation coefficients among growth and yield parameters of garlic at Kadawa 2007/2008 dry season.

\begin{tabular}{|c|c|c|c|c|c|c|c|c|c|c|c|}
\hline & 1 & 2 & 3 & 4 & 5 & 6 & 7 & 8 & 9 & 10 & 11 \\
\hline 1 & 0 & & & & & & & & & & \\
\hline 2 & $0.57^{* *}$ & 1 & & & & & & & & & \\
\hline 3 & $0.53^{* *}$ & $0.51^{* *}$ & 1 & & & & & & & & \\
\hline 4 & $0.28^{*}$ & $0.18 \mathrm{NS}$ & $0.67^{* *}$ & 1 & & & & & & & \\
\hline 5 & $0.06 \mathrm{NS}$ & -0.08 & $0.14 N S$ & $0.54^{* *}$ & 1 & & & & & & \\
\hline 6 & $0.57^{\star \star}$ & $0.42^{*}$ & $0.48^{* *}$ & $0.32^{*}$ & $0.05 \mathrm{NS}$ & 1 & & & & & \\
\hline 7 & $0.71^{* *}$ & $0.61^{* *}$ & $0.72^{* *}$ & $0.35 \mathrm{NS}$ & $\overline{0} .05 \mathrm{NS}$ & $0.50^{* *}$ & 1 & & & & \\
\hline 8 & $0.60^{\star *}$ & $0.63^{\star *}$ & $0.62^{* *}$ & $0.23 \mathrm{NS}$ & $-0.15^{\star *}$ & $0.53^{* *}$ & $0.79^{* *}$ & 1 & & & \\
\hline 9 & $0.47^{* *}$ & $0.43 \mathrm{NS}$ & $0.51^{* *}$ & $0.40^{*}$ & $0.14^{* *}$ & $0.31^{*}$ & $0.82^{* *}$ & $0.51^{* *}$ & 1 & & \\
\hline 10 & $0.61^{* *}$ & $0.56^{* *}$ & $0.64^{* *}$ & $0.17 \mathrm{NS}$ & $0.25^{* *}$ & $0.45^{*}$ & $0.76^{* *}$ & $0.79^{* *}$ & $0.27^{*}$ & 1 & \\
\hline 11 & $0.71^{* *}$ & $0.66^{* *}$ & $0.73^{* *}$ & $0.28^{*}$ & $\overline{0} 15 \mathrm{NS}$ & $0.55^{* \star}$ & $0.84^{* *}$ & $0.78^{* *}$ & $0.46^{*}$ & $0.89^{* *}$ & 1 \\
\hline
\end{tabular}

Key: $1=$ Plant height, $2=$ No. of leaves, $3=$ Total dry matter, $4=$ Crop growth rate (CGR), $5=$ Relative growth rate (CGR), $6=$ Fresh Bulb weight (g), $7=$ Cured bulb weight $(\mathrm{g}), 8=$ Bulb diameter, $9=$ Number of cloves, 10= Weight of cloves, 11= Cured bulb weight (Bulb Yield) (kg/ha), ${ }^{* *}=$ Significant at $1 \%$ level, ${ }^{*}=$ Significant at $5 \%$ level and NS= Not Significant 


\section{Nigerian Journal of Basic and Applied Science (June, 2017), 25(1): 58-62}

Table 2: Simple correlation coefficients among growth and yield characters of garlic at Kadawa 2008/2009 dry season.

\begin{tabular}{|c|c|c|c|c|c|c|c|c|c|c|c|}
\hline & 1 & 2 & 3 & 4 & 5 & 6 & 7 & 8 & 9 & 10 & 11 \\
\hline 1 & 1 & & & & & & & & & & \\
\hline 2 & $0.53^{\star *}$ & 1 & & & & & & & & & \\
\hline 3 & $0.71^{* *}$ & $0.62^{* *}$ & 1 & & & & & & & & \\
\hline 4 & $0.05 \mathrm{NS}$ & $0.01 \mathrm{NS}$ & $0.12 \mathrm{NS}$ & 1 & & & & & & & \\
\hline 5 & $0.05 \mathrm{NS}$ & $0.28^{* *}$ & $0.19 \mathrm{NS}$ & $-0.06 \mathrm{NS}$ & 1 & & & & & & \\
\hline 6 & $0.61^{* *}$ & $0.52^{\star *}$ & $0.56^{* \star}$ & $-0.07 N S$ & 0.24 & 1 & & & & & \\
\hline 7 & $0.56^{\star \star}$ & $0.48^{\star \star}$ & $0.67^{* *}$ & $-0.03 N S$ & 0.21 & $0.82^{* \star}$ & 1 & & & & \\
\hline 8 & $0.47^{* *}$ & $0.39^{* *}$ & $0.56^{* \star}$ & $-0.04 N S$ & 0.09 & $0.45^{*}$ & $0.58^{\star \star}$ & 1 & & & \\
\hline 9 & $0.26^{\star *}$ & $0.28^{\star *}$ & $0.66 \mathrm{NS}$ & $-0.03 \mathrm{NS}$ & 0.25 & $0.46^{*}$ & $0.53^{\star *}$ & $0.10 \mathrm{NS}$ & 1 & & \\
\hline 10 & $0.32^{\star \star}$ & $0.25 \mathrm{NS}$ & $0.63^{* *}$ & $-0.01 \mathrm{NS}$ & $0 . \overline{0}$ & $0.45^{*}$ & $0.54^{\star \star}$ & $0.51^{\star \star}$ & $-0.39^{*}$ & 1 & \\
\hline 11 & $0.60^{\star *}$ & $0.49^{* *}$ & $0.73^{* *}$ & $0.16 \mathrm{NS}$ & 0.1 & $0.54^{*}$ & $0.57^{\star *}$ & $0.56^{* *}$ & $0.04 \mathrm{NS}$ & $0.57^{\star *}$ & 1 \\
\hline
\end{tabular}

Key: $1=$ Plant height, 2= No. of leaves, $3=$ Total dry matter, 4= Crop growth rate (CGR), $5=$ Relative growth rate (CGR), $6=$ Fresh Bulb weight (g), 7= Cured bulb weight $(\mathrm{g}), 8=$ Bulb diameter, $9=$ Number of cloves, 10= Weight of cloves, 11= Cured bulb weight (Bulb Yield) (kg/ha), ${ }^{* *}=$ Significant at $1 \%$ level, ${ }^{*}=$ Significant at $5 \%$ level and NS= Not Significant

Table 3: Simple correlation coefficients among growth and yield characters of garlic at Kadawa for the combined (2007/2008 and 2008/2009) trials.

\begin{tabular}{|c|c|c|c|c|c|c|c|c|c|c|c|}
\hline & 1 & 2 & 3 & 4 & 5 & 6 & 7 & 8 & 9 & 10 & 11 \\
\hline 1 & 1 & & & & & & & & & & \\
\hline 2 & $0.54^{* *}$ & 1 & & & & & & & & & \\
\hline 3 & $0.55^{*}$ & $0.50^{*}$ & 1 & & & & & & & & \\
\hline 4 & $0.10 \mathrm{NS}$ & $0.02 \mathrm{NS}$ & $0.47^{* *}$ & 1 & & & & & & & \\
\hline 5 & $0.06 \mathrm{NS}$ & $0.11 \mathrm{NS}$ & $0.15^{\star \star}$ & $0.25^{*}$ & 1 & & & & & & \\
\hline 6 & $0.59^{* *}$ & $0.49^{* *}$ & $0.39^{* \star}$ & $-0.78 \mathrm{NS}$ & $0.13 \mathrm{NS}$ & 1 & & & & & \\
\hline 7 & $0.62^{* *}$ & $0.52^{\star *}$ & $0.50^{* \star}$ & $-0.06 \mathrm{NS}$ & $0.08 \mathrm{NS}$ & $0.76^{* \star}$ & 1 & & & & \\
\hline 8 & $0.55^{* \star}$ & $0.50^{* *}$ & $0.54^{\star *}$ & $0.01 \mathrm{NS}$ & $-0.03 \mathrm{NS}$ & $0.52^{* *}$ & $0.67^{* *}$ & 1 & & & \\
\hline 9 & $0.38^{* *}$ & $0.35^{* *}$ & $0.21^{*}$ & $-0.01 \mathrm{NS}$ & $0.19^{*}$ & $0.49^{* *}$ & $0.68^{* *}$ & $0.31 \mathrm{NS}$ & 1 & & \\
\hline 10 & $0.45^{* *}$ & $0.37^{* *}$ & $0.46^{* *}$ & $-0.11 \mathrm{NS}$ & $-0.11 \mathrm{NS}$ & $0.56^{* *}$ & $0.69^{* *}$ & $0.61^{* *}$ & $-0.02 \mathrm{NS}$ & 1 & \\
\hline 11 & $0.63^{* *}$ & $0.53^{* *}$ & $0.73^{* \star}$ & $0.25 \mathrm{NS}$ & $-0.05 \mathrm{NS}$ & $0.40^{* *}$ & $0.52^{* *}$ & $0.63^{\star *}$ & $0.15 \mathrm{NS}$ & $0.54^{* *}$ & 1 \\
\hline
\end{tabular}

Key: $1=$ Plant height, $2=$ No. of leaves, $3=$ Total dry matter, 4= Crop growth rate (CGR), $5=$ Relative growth rate (CGR), $6=$ Fresh Bulb weight (g), 7= Cured bulb weight $(\mathrm{g}), 8=$ Bulb diameter, $9=$ Number of cloves, 10= Weight of cloves, 11= Cured bulb weight (Bulb Yield) (kg/ha), ${ }^{* *}=$ Significant at $1 \%$ level, ${ }^{*}=$ Significant at $5 \%$ level and NS= Not Significant 


\section{CONCLUSION}

The research has shown that a significant and positive correlation was observed between total bulb yield/ha and other growth and yield characters except RGR (2007/2008), CGR and

\section{REFERENCES}

Akoun J. (2004). Effect of plant density and manure on the yield and yield components of common onion (Allium cepa L.) Vas. Nsukka Red. Nigeria Journal of Horticultural Science, 9:4348.

Aliuddin S. (1980). The effects of rate and time of nitrogen fertilizers application on the growth and yield of garlic ( $A$. sativum) Horticulture abstract, 53(12), 823-828, abstract 846 (1).

Aliyu B. S. (2006). Ethno -medicinal plants of semi- arid region of West African States. Triumph Publishing Company, Gidan Sa'adu zungur, Kano, Nigeria. Vol. 1 pp. 83-84.

Babaji B.A. (1996). Effects of plant spacing and nitrogen fertilization on growth and yield of garlic. M.Sc. thesis submitted to post graduate school, A.B.U, Zaria. Pp 44-48.

Bichi A.M. (1977). Response of garlic (Allium sativum L.) to varying levels of phosphorus and nitrogen. Unpublished B.Sc project submitted to the Department of Agronomy, A.B.U Zaria Pp 55-60.

Bodnar J., Omaf B. S., Omaf V. (1997). Garlic production. Horticulture published Biotech Books. Delhi Pp 33-35.

Borabash O.Y and Kochina, I.N. (1987). The effect of mineral fertilizers on garlic productivity. Putri intensifikasii Onoschevodist Vakiev, Ukranian, SSr (1987) 12-16 (Ccf; Horiculture, Abstract, 1990, 60(5) Abstract. 3284 Pp.380). number of cloves in the combined analysis. These characters should therefore not be considered if the aim is to increase/ improve yielding ability of garlic.

Duncan D.B. (1955). Multiple range and multiple F-test Biometrics 2:1 42.

Huber G.L. (2003). Medicinal uses of garlic in history. Texan nutrition Institute Vol. 5: Pp28-30

Islami M.J, A.K.N.A.M Hussein, F.Kharam, U.K. Majumder, M.M. Rahman and Saifur Rahaman, M. (2007). Effect of mulching and fertilization on growth and yield of garlic at Dinapur Bangladesh. Adian Journal of plant Science, 6(11) 98-101

Miko S., Ahmad M.K. Rufa'l, I. Dadari,S.A. and Falaki A.M. (1995). Simple correlation and path- Coefficient analysis between bulb yield and other components in garlic, $7^{\text {th }}$ Annual conference of Botanical Society of Nigeria, NAERLS, Ahmadu Bello University Zaria, Nigeria. Pp 18-21.

Miko S. (1999). Resonse of garlic (Allium Sativum L.) to levels of N.P and Irrigation interval. Unpublished PhD Thesis Ahmadu Bello University, Zaria, Nigeria. Pp. 219.

Miko S.A.M Falaki, M.A Hussaini and J.M Jibrin (2006). Simple correlation and path coefficient Analyses involving some growth parameters and bulb yield in garlic (Allium sativum $\mathrm{L}$ ). NJEAB/203/062.30, 7(1) 1-6.

Zakari S.M., Miko, S. and Aliyu, B.S (2014). Effect of different types and levels of organic manures on yield and yield components of garlic (Allium sativum L.) at Kadawa, Kano, Nigeria. BAJOPAS, 7(1):121-126. 